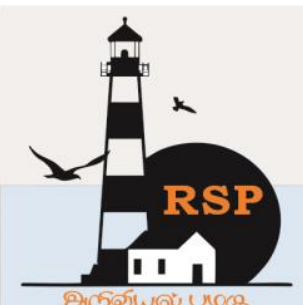

\title{
Rectangular Based Circular Slot Antenna for Ku Band Applications
}

Aswand $B^{1}$, Arundathi $S^{2}$, Merlinsuganya $K^{3}$.

${ }^{1} P G$ Student, Department of Electronics and Communication Engineering, Government College of Technology Coimbatore, Tamilnadu, India.

${ }^{2} U G$ Student, Department of Electronics and Communication Engineering, Government College of Technology Coimbatore, Tamilnadu, India

${ }^{31}$ PG Student, Department of Electronics and Communication Engineering, Government College of Technology Coimbatore, Tamilnadu, India

basaswa@gmail.com ${ }^{1}$

\begin{abstract}
Microstrip antenna plays a vital role in wide range of communication systems applications. microstrip antenna is the equipment connecting two are more devices by means of wireless connecting medium. in this manuscript, rectangular patch with circular slot antenna is presented, for ku band applications. Analysis of proposed antenna is carried out on HFSS 13.0 Simulator. Proposed antenna is designed on FR4 Epoxy substrate. The experimental result confirms the proposed antenna operates over the frequency of $13.99 \mathrm{GHz}$ to $16.61 \mathrm{GHz}$ with the impedance bandwidth of $18.3 \%$.far field of proposed radiator are stable and confirms its better performance in this frequency range.
\end{abstract}

Keywords: microstrip antenna, ku band applications, FR4 epoxy, HFSS13.0.

\section{Introduction}

Now a days, the microstrip antenna are used in various applications like, WLAN, WiMAX, Satellite communication, aircraft, remote control and telemetry. microstrip antenna is highly known to light weight, size,low cost and low profile.microstrip antenna consists of three parts named by a radiating element known to be microstrip patch, dielectric substrate, and ground plane.an all antenna elements with geometrical arrangement for improving of antenna gain, return loss, VSWR and highly directive radiation pattern for microwave antenna field. Although conventional microstrip antenna is highly advantage in terms of size and cost.it is unable to create omnidirectional radiation pattern in all planes as well as impedance bandwidth that is very less than 3\%.To overcome both these drawbacks slot antenna comes in to role.slot antenna works on the principle of magnetic dipole.it provides wider impedance bandwidth as compared to conventional microstrip antenna. A pair of $\mathrm{c}$ shaped at conductor backed plane is used for impedance matching. This antenna consists of square shaped patch as a radiator and slotted conductor backed plane. By adjusting the positions and lengths of these structures of slots on the conductor for backed plane.in this article triple slot antenna is designed and analyzed. In the proposed antenna design circular ring slot with $C$ shaped slot is used. Fair fields features of proposed antenna is stable in operating frequency. for better understanding of complete design procedure, Entire manuscript is divided in to five segments I) Introduction, II) Antenna geometry, III) Results and discussion, IV) conclusion, V) References. [1-4]

\section{Antenna Geometry}

The top and bottom view geometry of the 
www.rspsciencehub.com

proposed antenna is shown in figure 1 and 2 respectively.

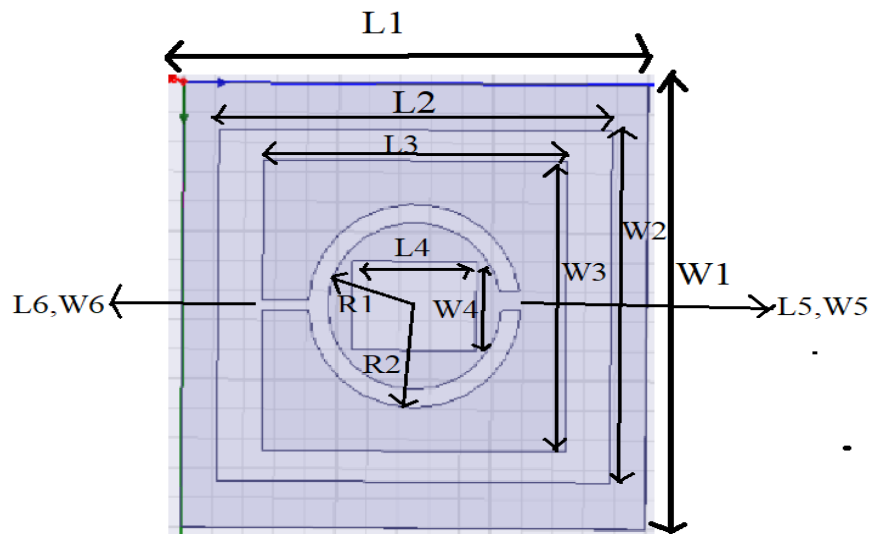

Fig.1 Top view geometry of proposed antenna

Rectangular slot along with C shaped slot is etching over FR4 substrate. The thickness of FR4 substrate is $0.8 \mathrm{~mm}$. its dielectric constant is 4.4 and loss tangent is 0.0148 respectively. on one side of the substrate rectangular patch of dimensions $(\mathrm{L} 1, \mathrm{~W} 1)$ is printed and then rectangular slots (L2,W2,L3,W3) and C shaped slots inner and outer side radius $(\mathrm{R} 1, \mathrm{R} 2, \mathrm{R} 3, \mathrm{R} 4)$ is etched. The $\mathrm{C}$ shaped slot is formed by combining a rectangular shaped slot. The length of connecting square patch is (L5,W5). The length and width of centre rectangular slot is (L4,W4). [5-9] A rectangular microstrip feed line is formed beneath the dielectric substrates. The dimension of the feed line is $(\mathrm{L} 7, \mathrm{~W} 7)$.the various dimensions of proposed radiator and location of feed line have been optimized using parametric analyses.Table 2.1 shows the every optimized dimension of proposed antenna. [10-12]

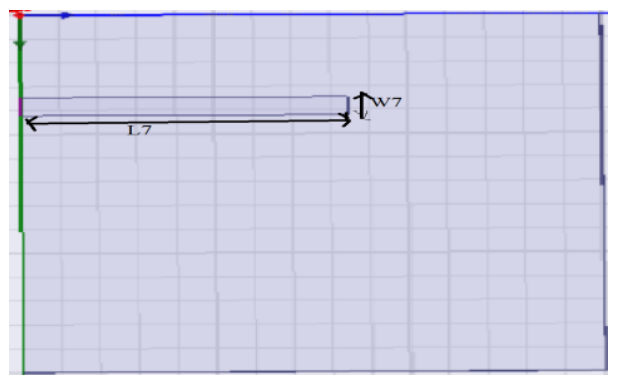

Fig.2 Bottom view geometry of proposed antenna

\section{RESULT AND DISCUSSION}

The simulation analysis has been performed using HFSS software (Ansoft's HFSS, version 13.0). HFSS is a finite element method based solver for electromagnetic structures.
Volume 02 Issue 06 June 2020

Table.1. Parameters for proposed antenna

\begin{tabular}{|l|l|}
\hline PARAMETERS & UNITS (mm) \\
\hline Length of the substrate/patch (L1) & 15 \\
\hline Width of the substrate/patch (W1) & 15 \\
\hline Length of the outer rectangle (L2) & 12.7 \\
\hline Width of the outer rectangle (w2) & 11.875 \\
\hline Length of the inner square (L3) & 9.8 \\
\hline Width of the inner square (w3) & 9.8 \\
\hline Length of the inner rectangle (L4) & 4 \\
\hline Width of the inner rectangle (W4) & 3 \\
\hline Length of the gap (L5) & 0.668 \\
\hline Width of the gap (W5) & 0.625 \\
\hline Length of the connecting slot (L6) & 1.46 \\
\hline Width of the connecting slot (W6) & 0.3125 \\
\hline Length of the microstrip line (L7) & 8.4375 \\
\hline Width of the microstrip line (W7) & 0.78125 \\
\hline Radius of the inner circle (R1) & 2.8125 \\
\hline Radius of the outer circle (R2) & 3.4375 \\
\hline Height of the substrate (H) & 0.8 \\
\hline
\end{tabular}

\subsection{RETURN LOSS}

Return loss is for mismatched load, if load is mismatched then energies losses concern with no better quality so all power is not transfer to load from source is called return loss. The peak return loss is founded to be $-37.2 \mathrm{~dB}$ at $14.45 \mathrm{GHz}$

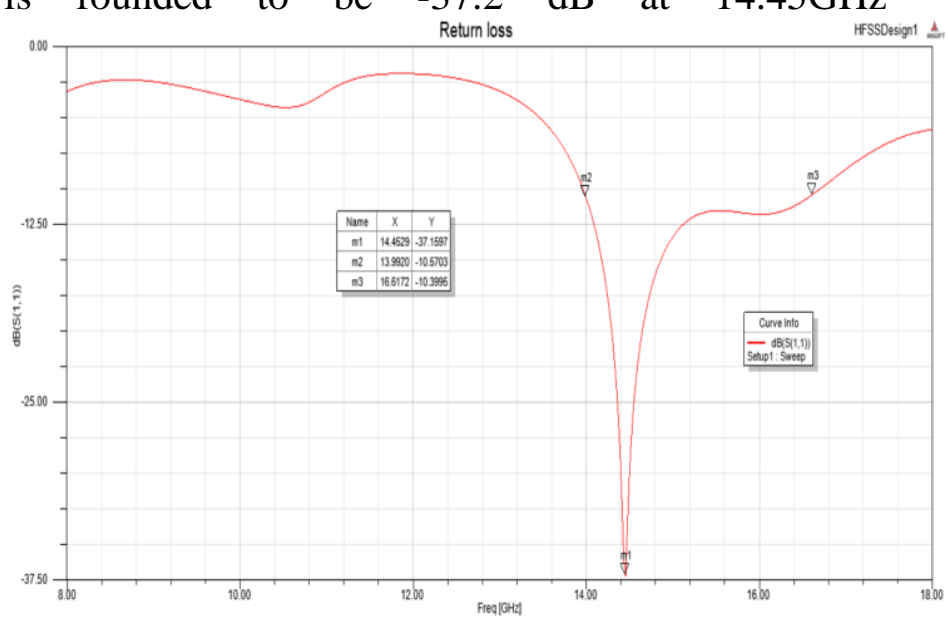

Fig.3. Return loss or S11 parameter for proposed antenna

The reflection coefficient of S11 parameter bandwidth are achieved $(\mathrm{S} 11<-10 \mathrm{~dB})$ from 13.99 to $16.62 \mathrm{GHz}(18.3 \%)$.Table. 2 shows the return loss in $\mathrm{dB}$ versus frequency of S11 parameter. 
Table.2 Return loss in $\mathrm{dB}$ versus frequency of reflection coefficient.

\begin{tabular}{|r|r|}
\hline Freq [GHz] & $d B(S(1,1))[]$ \\
\hline 13.9060403 & -9.1913766 \\
\hline 13.9731544 & -10.242057 \\
\hline 14.0402685 & -11.492855 \\
\hline 14.1073826 & -13.015229 \\
\hline 14.1744966 & -14.929393 \\
\hline 14.2416107 & -17.454875 \\
\hline 14.3087248 & -21.044083 \\
\hline 14.442953 & -37.438944 \\
\hline 14.5100671 & -28.461789 \\
\hline 14.5771812 & -23.109015 \\
\hline 14.6442953 & -20.028631 \\
\hline 14.7114094 & -17.930129 \\
\hline 14.7785235 & -16.384031 \\
\hline 14.8456376 & -15.199934 \\
\hline 14.9127517 & -14.275873 \\
\hline 14.9798658 & -13.549626 \\
\hline 15.0469799 & -12.979607 \\
\hline 15.114094 & -12.536147 \\
\hline 15.1812081 & -12.197005 \\
\hline 15.2483221 & -11.944812 \\
\hline 15.3154362 & -11.765495 \\
\hline 15.3825503 & -11.647234 \\
\hline 15.4496644 & -11.579731 \\
\hline 15.5167785 & -11.553668 \\
\hline 15.5838926 & -11.560301 \\
\hline 15.6510067 & -11.591152 \\
\hline 15.7181208 & -11.637792 \\
\hline 16.657718 & -10.21975 \\
\hline 145989
\end{tabular}

\subsection{VSWR}

VSWR is function of reflection coefficient it shows reflected power from antenna.it always real and positive number of antenna.Smaller the VSWR then the design is perfectly matched with transmission line to antenna and no power is reflected from antenna.

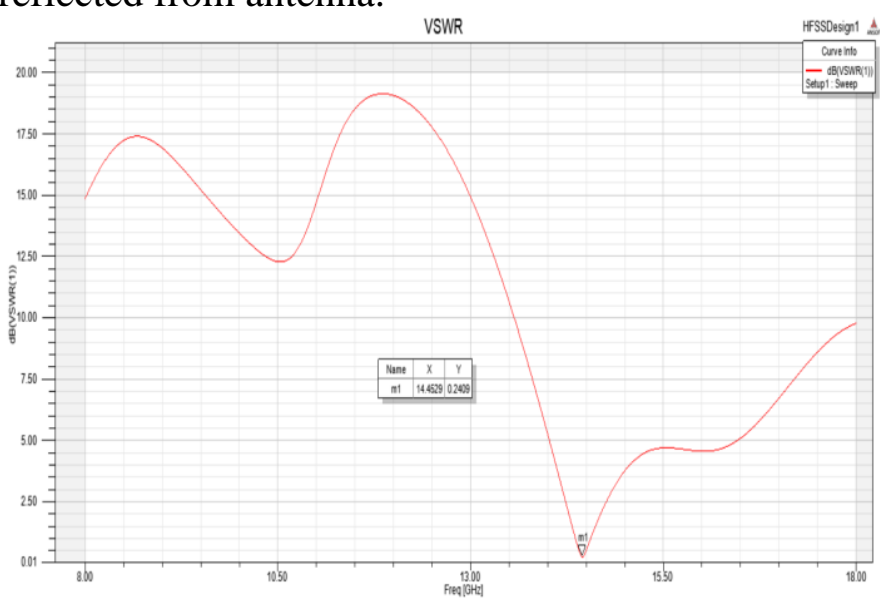

Fig.4.VSWR analysis for proposed antenna

VSWR for proposed antenna is 0.2409 ,therefore reflection coefficient will be 0.8058 .

$$
\tau=\text { Reflection Coefficient }
$$

$$
\begin{gathered}
S=\frac{1+\tau}{1-\tau} \\
S(1-\tau)=1+\tau \\
\tau=\frac{S-1}{S+1}
\end{gathered}
$$

$\operatorname{VSWR}=0.2409$

$$
|\tau|=0.8058
$$

\subsection{RADIATION PATTERN}

Radiation pattern of an antenna represent energy radiates or reflects by antenna in free space.Radiation pattern are representation of the distributed radiated energy in to space as function of direction. The radiation characteristics of antenna is investigated. The simulation result shows antenna exhibited good radiation pattern at operating frequency.

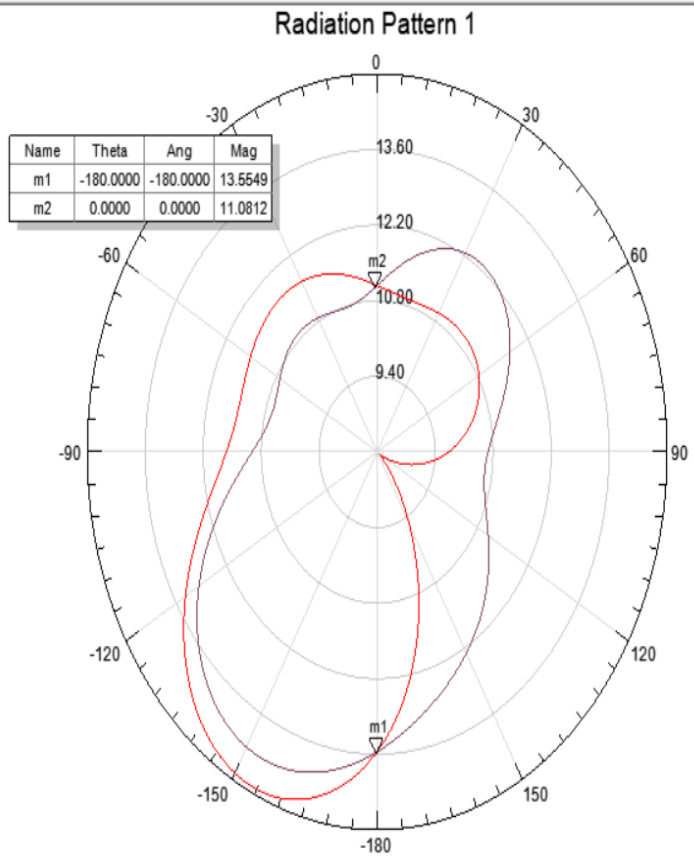

Fig.5.Radiation pattern for proposed antenna

$$
\operatorname{VSWR}=\frac{1+\tau}{1-\tau}
$$




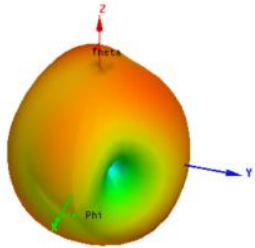

Fig.6. 3D Radiation pattern for proposed antenna

\subsection{PEAK DIRECTIVITY}

Peak Directivity is the measure of the concentration of an antenna"s radiation pattern in a particular direction. If the Directivity is high the designed antenna is more concentrated on beam, the proposed antenna directivity is measured to be $1.2986 \mathrm{~dB}$.

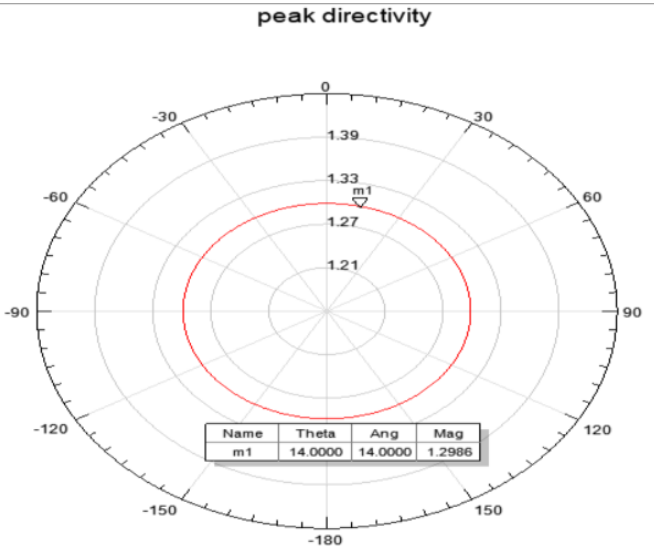

Fig.7.Peak Directivity for proposed antenna

\subsection{PEAK GAIN}

Peak gain shows how much power is transmitted in the direction of peak radiation to that of isotropic source.

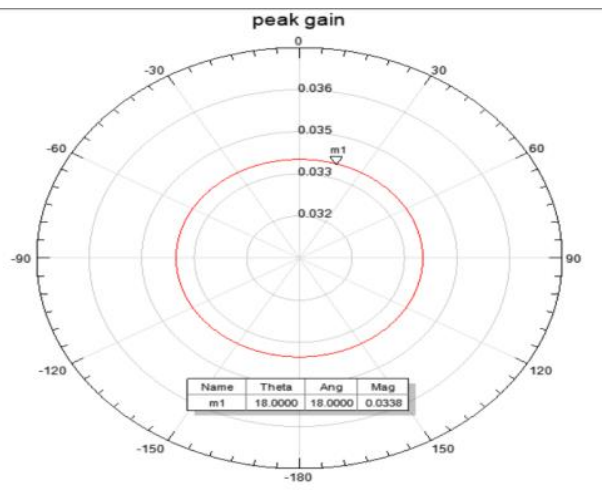

Fig.8.Peak Gain for proposed antenna

\subsection{RADIATION EFFICIENCY}

Radiation efficiency shows how effectively antenna radiates to a particular distance.

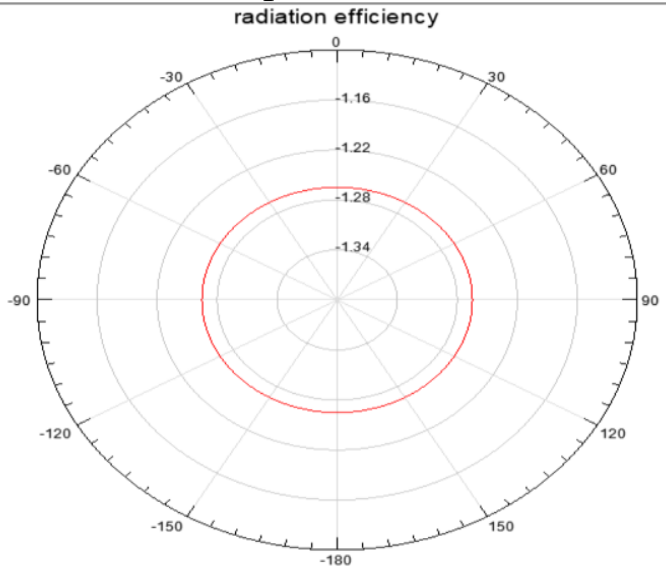

Fig.9.Radiated efficiency for proposed antenna

\subsection{E AND H FIELD PATTERN}

In $\mathrm{E}$ field and $\mathrm{H}$ field pattern that red and orange color shows maximum radiation of antenna.

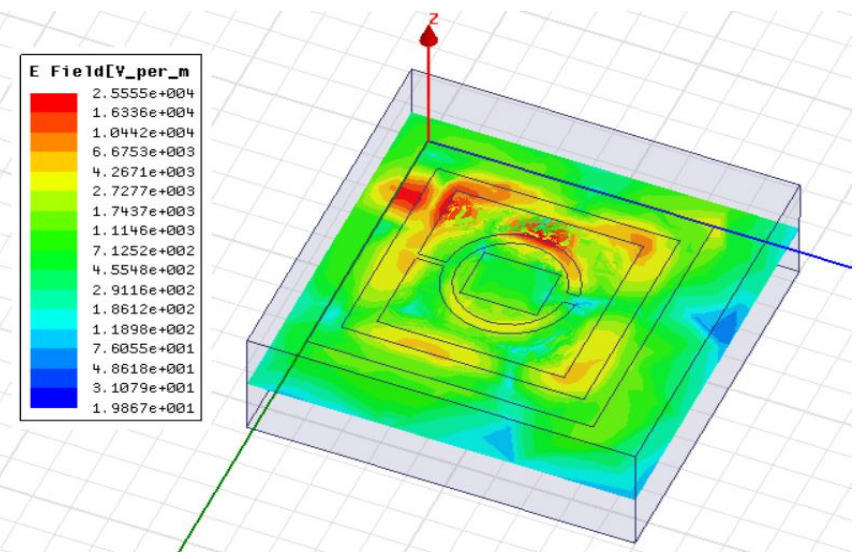

Fig.10 E Field for proposed antenna

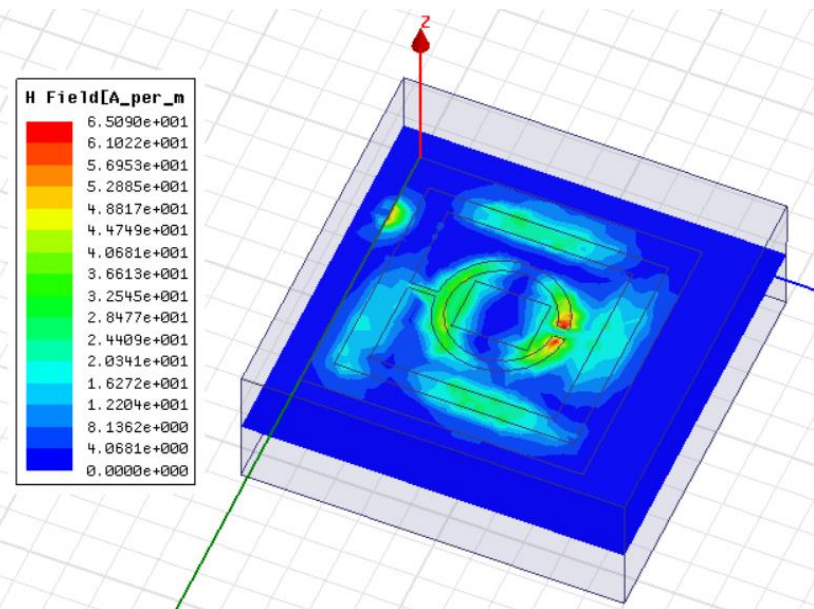

Fig.11 H Field for proposed antenna 
Table.3.Overall parameter

\begin{tabular}{|l|l|}
\hline Parameters & Values \\
\hline Resonance frequency & $14.45 \mathrm{GHz}$ \\
\hline Return loss & $-37.1597 \mathrm{~dB}$ \\
\hline Gain & $11.0812 \mathrm{~dB}$ \\
\hline VSWR & 0.2409 \\
\hline Directivity & $1.2986 \mathrm{~dB}$ \\
\hline
\end{tabular}

\section{Conclusion}

This manuscript describes the design and radiation performance of an rectangular based circular slot antenna for ku band applications.Frequency band $14 \mathrm{GHz}$ is due to an rectangular slot coupling with an $C$ shaped slots.after evaluating all the performance parameters, it can be said that the proposed antenna radiation is suitable for an $\mathrm{KU}$ band applications.In future by inserting an circular ring shaped slot along with an $U$ shaped slot provides a dual band frequencies because wireless communication system widely requires a radiator, which can be capable of supporting multiple frequency ranges as well as it can provide high SNR without demanding requirement of extra power level.

\section{References} BOOKS

[1] Balanis CA. Antenna Theory, Analysis and Design. New Jersey: John Wiley \& Sons; 2005.

[2] Garg R, Bhartia P, Bahl I, Ittipiboon A. Microstrip Antenna Design Handbook. Norwood: Artech House; 2001.

[3] James JR, Hall PS. Handbook of Microstrip Antennas. London: Peter Peregrines Ltd; 1989.

\section{JOURNAL}

[4] Zhang T, Li RL, Jin GP, Wei G, Tentzeris MM. A novel multiband planar antenna for GSM/UMTS/LTE/Zigbee/RFID mobile devices. IEEE Trans Antennas Propag. 2011;59(11):4209-4214.

[5] Naser-Moghadasi M, Sadeghzadeh RA, Fakheri M, Aribi T, Sedghi T, Virdee BS. Miniature hook-shaped multiband antenna for mobile applications. IEEE Antennas Wireless Propag Lett. 2012;11:1096-1099.

[6] Bakariya PS, Dwari S, Sarkar M, Mandal MK. Proximity coupled microstrip antenna for Bluetooth, WiMAX and WLAN applications. IEEE Antennas Wireless Propag Lett. 2014;14:755-758.

[7] Wong KL, Yang KP. Small dual-frequency microstrip antenna with cross slot. Electronics Lett. 1997;33(23):1916-1917.

[8] Chen HD. A dual-frequency rectangular microstrip antenna with a circular slot. Microw Opt Technol Lett. 1998;18(2):130132.

[9] Chen WS. Single-feed dual-frequency rectangular microstrip antenna with square slot. Electron Lett. 1998;34(3):231-232.

[10] Yang YH, Guo JL, Sun BH, Huang YH. Dual-band slot helix antenna for global positioning satellite applications. IEEE Trans Antennas Propag. 2016;64(12):5146-5152.

[11] Hung C, Chiu T. Design of dualband cavity-backed slot antenna loaded with spurline. IET Microw Antennas Propag. 2016;10(9): 939-946.

[12] Kandasamy K, Majumder B, Mukherjee J, Ray KP. Dual-band circularly polarized split ring resonators loaded square slot antenna. IEEE Trans Antennas Propag. 2016;64(8):3640-3645. 